\title{
Student Styles and Learning in Two College of Business Courses
}

\section{Blair Lord}

The University of Rhode Island

In teaching junior and senior finance and insurance courses, courses which must be applied in their emphasis, I think it important to concentrate on developing problem solving skills. Sometimes this means solving straight-forward, technical problems. At other times I focus on more open-ended managerial or public policy problems. While not wanting to foster a "technical school" mentality, the career orientation of business disciplines makes it appropriate to focus on developing the students' ability to apply course material. An ancillary benefit from this orientation is that it nurtures problem solving and analytical skills generally.

To accomplish this objective, I have sought to involve students in a substantial amount of problem solving in classroom small group activities and in their homework assignments. Informal student feedback indicates that this approach is different from that usually experienced by students in the College of Business Administration. I also have received very different reactions from individual students about how they liked my teaching style and class activities. Undoubtedly, whatever we do or do not do in class is fated to be received differently by different students; however, I am convinced that there must be a systematic relationship between the learning styles my students bring to my classes and the ways they respond to my courses and the teaching methods I use.

From To Improve the Academy: Resources for Student, Faculty, and Institutional Development, Vol. 7. Edited by J. Kurfiss, L Hilsen, S. Kahn, M.D. Sorcinelli, and R. Tiberius. POD/New Forums Press, 1988. 
Although there is a substantial literature on learning styles, learning style researchers come from different disciplines, focus on different dimensions of perception and learning, employ different methodologies and instruments, and come to different conclusions about which variables define one's learning style and about their effect on learning. Thus, the research is fragmented and the extent to which learning styles can affect students' acquisition of knowledge in general and learning in specific activities is still highly speculative; nevertheless, the existence of some measurable impact has intuitive appeal.

Two issues are the focus of this study. First, how do different "types" of students respond to the style of presentation and learning activities employed in the courses I teach? That is, how well do different types of students perform in my classes and how do they like what I have them do? Second, can information about students' learning styles enhance my teaching?

\section{Method}

As noted, there are several different categorizations of students which can be found in the literature. For this study, three were used: the Myers-Briggs Type Indicator, Abbreviated Version (Briggs \& Meyers, 1983), the Learning Style Inventory (Kolb, 1985), and LOGO II (Eison, Pollio \& Milton, 1982). They were chosen for several reasons: their widespread usage, the availability of straight-forward classification instruments, my familiarity with the typologies, and my belief that these categorizations might have some measurable association with the performance and attitudes of my students (see Claxton \& Murrell, 1987, for a good introduction to these and other instruments). The MBTI uses four dichotomous scales to classify students: (1) extraverted/introverted; (2) sensing/intuitive; (3) thinking/feeling; and (4) judging/perceptive. Kolb's LSI identifies four learning styles - divergent, convergent, assimilating, and accomodating - on the basis of student preferences along two dimensions: concrete/abstract and reflective/active. The LOGO II assesses learning and grade orientations. For this study, students were sorted into high, medium, or low learning and grade oriented groups of approximately equal size on the basis of their scores.

Two junior-level business administration classes were studied: two 40-student sections of a financial institutions course in the fall semester, and a commercial property-liability insurance course with 16 students in the spring. In the financial institutions course, Kolb's LSI and Eison's LOGO II were administered in the second week of the semester. I also 
collected ratings on a simple 1-10 scale (1 being "terrible" and 10 "excellent") of one small group activity and of the essay and objective sections of the first midterm. Scores on the two midterms and final exams also were available, including subscores for the essay and objective sections. The LSI, LOGO II, and student ratings were administered by someone from the Instructional Development Program so that students could include their names without my knowing any individual's responses. I had expected to collect more student ratings of activities and exams, but it was the first time I had taught the course and in the scramble to keep up I found it difficult to plan ahead for such things.

The LSI, LOGO II, and MBTI (Abbreviated Version) were administered in the second week of the spring semester in the insurance course. The students also rated the two midterms (these examinations contained essay questions exclusively), a small group activity, and a traditional lecture during the semester. I used the same 1-10 scale during the last class period for students to rate homework problems, classroom problem sheets on the insurance contracts and their use in small group problem solving sessions, classroom discussion of the problems sheets, lectures, and other classroom discussions. Finally their exam scores were available.

\section{Results}

Almost half of the fall semester students were classified as "assimilators" by the LSI. Such students excel in inductive reasoning. They are good in creating theoretical models after having collected many disparate observations. Assimilators tend to gravitate toward the physical and social sciences. The remaining students were evenly distributed as "accommodators," "divergers" and "convergers." Interestingly, Kolb has found that the business professions are dominated typically by accommodators (Kolb, 1984).

Although LOGO II results showed my students to be somewhat more learning than grade oriented (the means were 45.17 and 43.79 , respectively), their scores on both dimensions were higher than those reported by Eison (undated) for another, broader cross-section of college students.

The four Kolb categories and the two LOGO II dimensions were cross-tabulated with the student ratings and test scores described earlier. Only a few comparisons turned up differences which were statistically significant at a $10 \%$ rejection level. Specifically, convergers performed better on the essay portions of the last two exams, while the divergers did the worst on every test subscore but the first exam essay and the final exam 
objective. Although the differences were not statistically significant, the divergers consistently rated the exams most negatively as well.

The LOGO II comparisons did not show any statistically significant contrasts. In general, the high learning oriented group seemed to do better on my tests, particularly the essay portions, and rated them more highly than the other groups. In contrast, the high grade orientation group tended to perform more poorly and respond more negatively to the tests. Student performance on the final examination essay was inversely related to grade orientation.

Results for my spring semester course were limited by the small sample size, a problem exacerbated by some missing observations for the rating measurements. Generally, however, MBTI extroverts $(n=10)$ and sensing/thinking types $(n=9)$ liked the small group, interactive activities. There also was a positive relationship between learning orientation and ratings of my lectures. Otherwise, there were no statistically significant contrasts or suggestive patterns.

\section{Discussion}

Did my students' performance and rating of these classes vary with their learning styles? While the results were not definitive, there was some evidence that student learning styles did make a difference in how they responded. Students classified as convergers generally did best and responded most favorably to the teaching methods I used. The divergers tended to fall at the other extreme in performance and ratings of satisfaction. In like manner, those ranked highest in learning orientation seemed to respond more favorably than those with the highest grade orientation.

A more thorough study with a larger sample would probably help me resolve some of the ambiguities in these results. Only a few of the learning style categories showed any statistically significant association with class performance or ratings of satisfaction with specific activities. I'd like to see if those same relationships would turn up again. I'd also like to know if particular learning style types, convergers and learning oriented students in this instance, are simply more successful in business school courses like mine.

Nevertheless, I believe that even these modest results have implications for my teaching. As I claimed in my syllabus and opening lecture, I want my students to be able to solve not only technical problems but to be able to analyze some managerial and public policy questions as well. My hope has been that they would be able to synthesize information and opposing opinions on such problems and draft and defend their solutions. 
The strong showing of convergers, who are high on "active experimentation," together with the weak showing of divergers, who are high on "reflective observation," suggests that I've not been as successful with that as I had hoped. On the other hand, the success and favorable ratings of the high learning oriented students implies that I have managed to engage successfully with those predisposed to learn and think about the material.

Because student learning styles apparently do matter, more variability in my teaching would be helpful, particularly for the divergers. Where appropriate, having some activities designed to meet the needs of each type of student would be helpful. Also, I need to reflect on the nature of the methods I am using now; they are not doing all that I thought they were in terms of developing and rewarding certain learning skills and tendencies.

\section{References}

Briggs, K. C., \& Meyers, I. B. (1983). Meyers-Briggs type indicator, abbreviated version. Palo Alto, CA: Consulting Psychologists Press, Inc.

Claxton, C. S., \& Murrell, P. H. (1987). Learning Styles: implications for improving educational practice. ASHE-ERIC Higher Education Report No. 4. Washington, D.C.: Association for the Study of Higher Education.

Eison, J. (undated). Recognizing and responding to learning style differences. Unpublished manuscript, Southeast Missouri State University, Center for Teaching and Learning, Cape Girardeau.

Eison, J., Pollio, H., and Milton, O. (1982). Manual for use with LOGO II. Knoxville, TN: Learning Research Center, The University of Tennessee.

Kolb, D. (1984). Experiential learning: Experience as the source of learning and development. Englewood Cliffs, NJ: Prentice-Hall.

Kolb, D. (1985). The learning-style inventory. Boston, MA: McBer and Company. 